\title{
Comparison of wind tunnel and on site measurements for urban wind energy estimation of potential yield
}

\author{
Ayman Al-Quraan*, Ted Stathopoulos, Pragasen Pillay \\ Centre for Zero Energy Building Studies, Faculty of Engineering and Computer Science, Concordia University, Montreal, Canada
}

\section{A R T I C L E I N F O}

Article history:

Received 8 March 2016

Received in revised form 20 August

2016

Accepted 26 August 2016

Available online xxx

\section{Keywords:}

Equiterre building

Airport data

Urban wind measurements

Wind energy

Wind tunnel

Wind speed estimation

Energy estimation

\section{A B S T R A C T}

There is a need to compare wind tunnel results with field measurement wind data in order to examine the validity of wind tunnel data in providing realistic estimates of urban wind energy potential and assess the probable errors involved. The paper refers to and discusses two Montreal building cases with different upstream roughness homogeneity. In the first case, field wind speed measurements are used to calculate the wind energy potential for a building with upstream rather homogeneous suburban type of terrain. In the second case, the building upstream terrain is very rough and highly nonhomogeneous. The calculated wind energy potential based on the field measurements was compared with the estimated value based on respective boundary layer wind tunnel data. In the first case, where the upstream terrain is homogeneous, the difference between the estimation of wind energy potential and the calculation using the field measurements is less than $5 \%$. However, in the second case with the nonhomogeneous upstream terrain conditions, the difference between the estimation of the wind energy potential and the calculation using the field measurements is increased by up to $20 \%$.

CC 2016 Published by Elsevier Ltd.

\section{Introduction}

Urban energy generation such as that produced by reduced-scale wind turbines installed on or around buildings can be defined as micro-generation. Recently, there is a growing interest in the use of wind energy in buildings for distributed generation. Since the generated power is a function of the cube of the wind speed, a small increase in the wind speed leads to a large difference in wind energy generation.

The prediction of the wind speed in the built environment is difficult, due to the roughness and the frictional effects, which reduce the wind speed close to the ground. In addition, several adjacent buildings influence the wind regime around a specific building in the urban environment. The most dependable method for the wind assessment in the urban environment is to directly measure the wind speed, ideally at the position and the height of the proposed wind turbine. However, measuring the wind speed at a site is both time consuming and expensive, i.e. normally not appropriate for the early stages of wind energy development. Fortunately, several methods are available for the initial assessment of wind resource in urban areas, with varying degrees of resolution and accuracy. These are, in order of increasing accuracy, wind atlases, numerical methods including CFD, wind tunnel modeling and direct wind resource measurement (European Commission, 2007).

A wide range of wind atlases is available at the continental and national level. In Canada, the Canadian wind energy atlas - http:// www.windatlas.ca - covers a wide area but its low resolution means

* Corresponding author. that it can only give a general picture of the wind resource. Another issue is that the wind atlases cannot take into account the local variations and their effect on the wind distribution.

On a more refined scale, wind speeds can be determined by using wind tunnel models, which must be combined with data at known locations. This role is usually fulfilled by local meteorological station measurements, other weather-related recorded data or airport data. The wind tunnel tests are used to give a more accurate estimate of wind without actually undertaking a wind measurement campaign.

The performance of a wind turbine in the built environment is only successful when there is adequate wind supply for it. Therefore, buildings exposed to either undisturbed or, even better, accelerated wind flows would be expected to augment their wind energy potential, as also mentioned by Arriago (2009) referring to buildings higher than their directly adjacent buildings. Many different types of wind turbines exist for the urban environment and they can be divided into two main groups depending on the orientation of their axis of rotation: Horizontal Axis Wind Turbine (HAWT) and Vertical Axis Wind Turbine (VAWT). A typical example of HAWTs associated with the Bahrain World Trade Center is shown in Fig. 1. It has been reported that these turbines provide about $11-15 \%$ of the building's power consumption (https://commons.wikimedia.org/wiki/ File:Bahrain_World_Trade_Center.jpg?uselang=nl).

This paper is organized as follows: Section 2 refers to wind modeling and describes the wind tunnel facility and the instrumentation used in the measurements of this study, Section 3 describes the methodology used in the estimation of the wind energy and in Sections 4 and 5 this methodology has been tested using rather homo- 


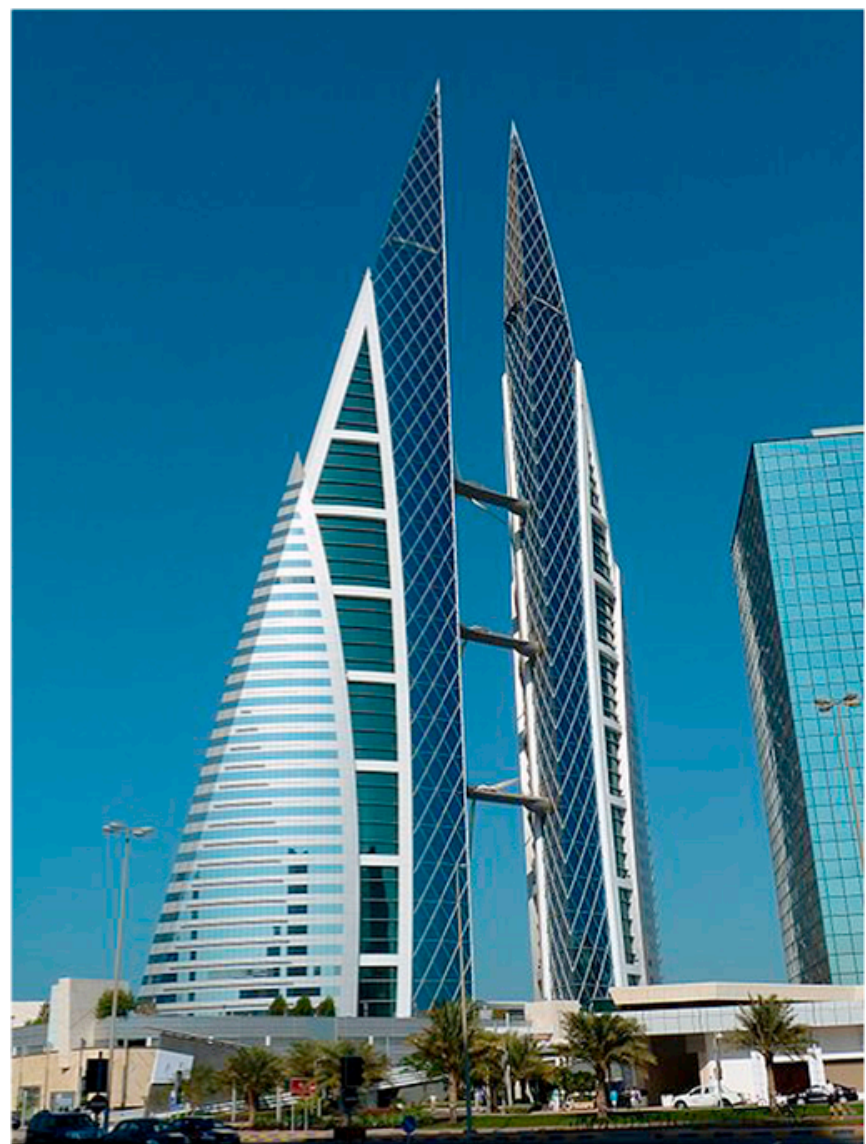

Fig. 1. : Urban Wind Turbines: Bahrain World Trade Center Towers. (https:// commons.wikimedia.org/wiki/File:Bahrain_World_Trade_Center.jpg?uselang=nl).

geneous and nonhomogeneous case studies prior to concluding in Section 6 .

\section{Wind modeling and experimental facilities}

For winds near the ground surface, frictional effects play a significant role. Ground obstructions retard the movement of air close to the ground surface, causing a reduction in wind speed. At some height above ground, the movement of air is no longer affected by ground obstruction. This height is called gradient height $Z_{G}$ which is a function of ground roughness. The unobstructed wind speed is called gradient wind speed, $V_{z_{G}}$ and it is considered to be constant above gradient height. The power law, which is used by some engineers to represent the variation of wind speed with height, is an empirical equation, which for the case of mean speeds takes the form of:

$$
\frac{V_{Z}}{V_{Z_{G}}}=\left(\frac{Z}{Z_{G}}\right)^{\alpha}
$$

where:

$Z_{G}$ Gradient height $\alpha$ Power-law exponent

Both variables are functions of the ground roughness. Typical values of $Z_{G}$ and $\alpha$ are given in Table 1. Fig. 2 shows typical variations of wind speeds above different ground roughness (Stathopoulos, 2007).
Table 1

Suggested Values of $\boldsymbol{Z}_{\boldsymbol{G}}$ and $\boldsymbol{\alpha}$ for Various Terrain Conditions (Davenport, 1960, modified)

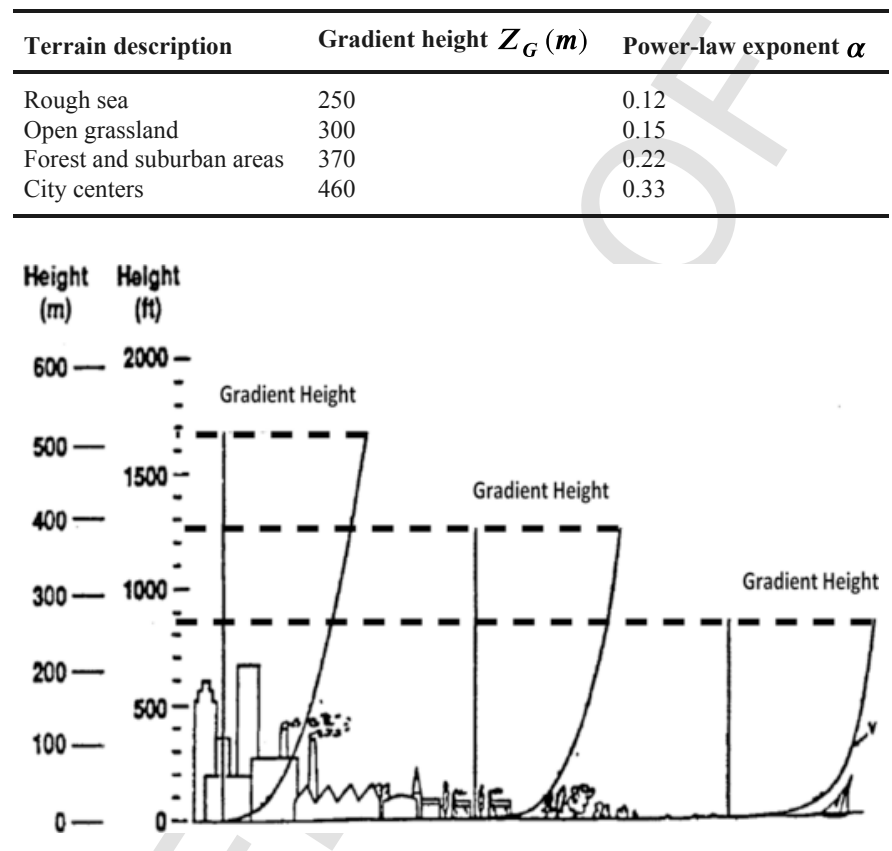

Fig. 2. : Variation of Wind Speed with Height (Stathopoulos, 2007).

Wind tunnels have been a key element in scientific research in a number of fields. Since the 19th century, experimenting with race cars, airplanes, weather patterns, and various other areas has been made much easier because of this development. Moreover, wind tunnels have a variety of important uses in the world today including the design of buildings (Vasan and Stathopoulos, 2014). A photo of the atmospheric boundary layer wind tunnel of Concordia University is shown in Fig. 3. This wind tunnel is $12.2 \mathrm{~m}$ in length and $1.8 \mathrm{~m}$ in width with a suspended roof that allows the height to be adjusted between $1.4 \mathrm{~m}$ and $1.8 \mathrm{~m}$. The wind tunnel can be operated at velocities from $3 \mathrm{~m} / \mathrm{s}$ to $14 \mathrm{~m} / \mathrm{s}$. A turntable, $1.6 \mathrm{~m}$ diameter, at the test section allows the model to be rotated to account for different wind directions. Details regarding this wind tunnel, its roughness features used

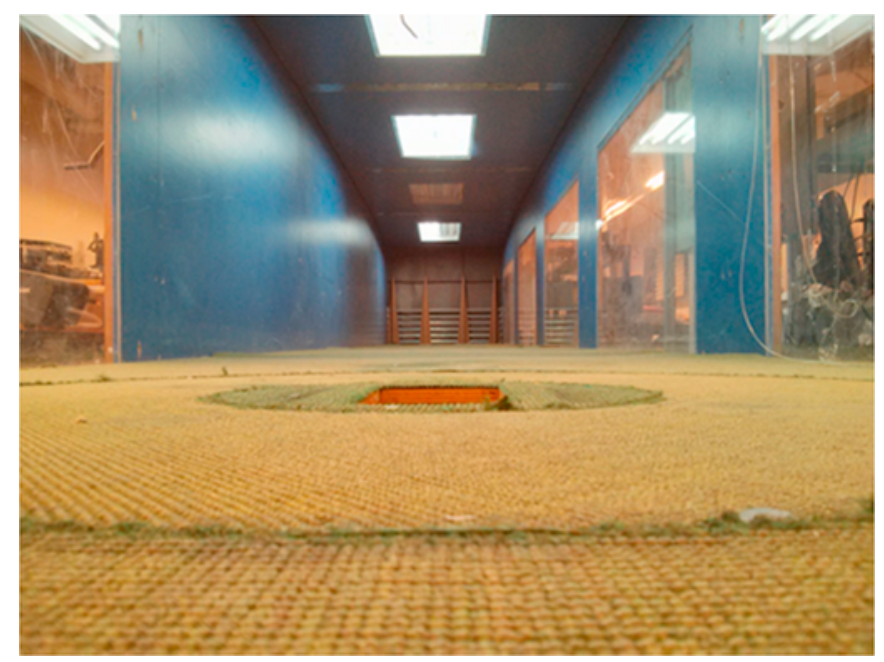

Fig. 3. : View of Test Section and Upstream Fetch of Atmospheric Boundary Layer Wind Tunnel at Concordia University. 
to generate the atmospheric boundary layer profiles and turbulence characteristics can be found in Stathopoulos (1984); additional discussion and applications in Mathew et al. (2002).

Graphical user interface and data acquisition software of the instrument enable the control of the measurement process and display of the data on a computer screen in real time. The software stores these data in text files that can easily be imported into a spreadsheet (Vasan and Stathopoulos, 2014). A three-dimensional (3-D) traversing-gear system attached to the wind tunnel ceiling above the test section enables accurate positioning of velocity measurement devices at points of interest on the model. During the wind tunnel tests, a Cobra probe is mounted onto the 3-D traversing arm and positioned on the model using a control system whereby Cartesian co-ordinates of the points of interest are entered.

A standard 3-cup anemometer was used for all field wind velocity measurements carried out in this study.

\section{Methodology for wind energy estimation}

Consider a case of wind energy estimation above the roof of a building in a city, say Montreal. The wind speed is measured in meteorological stations or at airports usually at $10 \mathrm{~m}$ height from the ground level, as established by the World Meteorological Organization (WMO). In this case the wind speed is measured at Montreal's Dorval (Pierre Elliott Trudeau, PET) Airport and denoted by $v_{1}$. The target is to estimate the wind velocity over a specific position at the roof of building $\mathrm{X}$ denoted by $v_{3}$, as shown schematically in Fig. 4. At Dorval (PET) Airport in Montreal, the 10's degree convention is used to determine the direction of the wind speed in which 9 means 90 degrees true or an east wind, and 36 means 360 degrees true or a wind blowing from the north. A value of zero denotes a calm wind. Fig. 5 shows the yearly wind rose of Montreal, where the wind direction distribution is presented in a percentage form.
In Montreal the prevailing wind direction is variable but coming mainly from south-west (SW). According to the 10's degree convention, the SW fetch is characterized by a number between 18 (South) and 27 (West). In order to obtain the best estimation of wind energy, all wind directions from the south west fetch will be considered, i.e. numbers from 18 to 27 , and every two steps from other directions i.e. numbers $1,3,5, \ldots, 15$ and 18-27, then 29, 31, 33, 35 (Al-Quraan et al., 2014a, 2014b).

$$
\frac{v_{1}}{V_{G}}=\left(\frac{10}{Z_{G O T}}\right)^{\alpha_{O T T}}
$$

where:

$v_{1}$ wind speed at Dorval (PET) Airport.

$V_{G}$ gradient wind speed.

$Z_{G O . T}$ gradient height for open terrain.

$\alpha_{O \text {.T }}$ power-law exponent for open terrain exposure.

The wind speed upstream of the site of interest $\left(v_{2}\right)$ can be estimated by considering urban upstream roughness as follows:

$$
\frac{v_{2}}{V_{G}}=\left(\frac{Z_{X}}{Z_{G U r b}}\right)^{\alpha_{U r b}}
$$

where:

$v_{2}$ wind speed upstream the site of interest at the same level of the assumed anemometer above the roof.

$Z_{G U r b}$ gradient height for urban area.

$Z_{X}$ height of the installed anemometer over the building roof.

$\alpha_{U r b}$ power-law exponent for urban terrain.

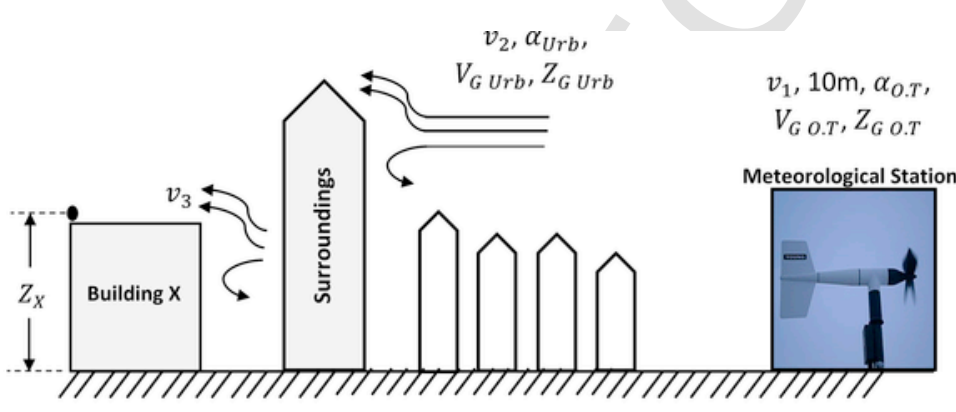

(a)

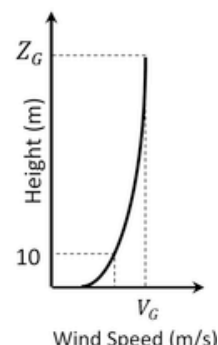

Wind Speed $(\mathrm{m} / \mathrm{s})$

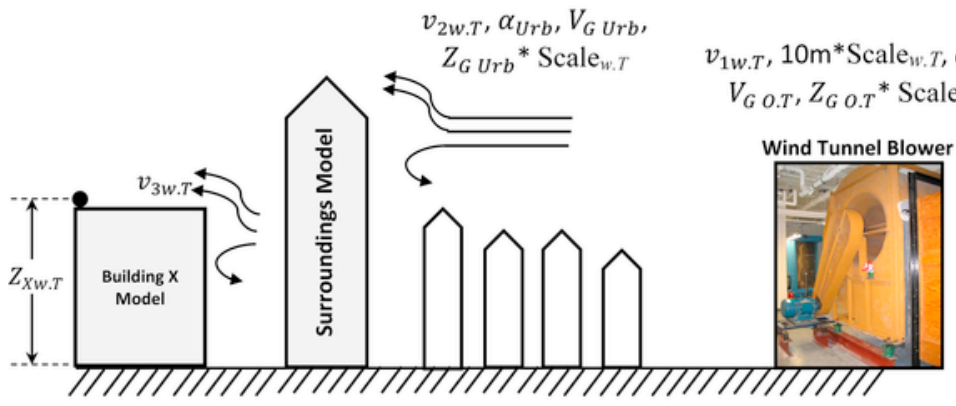

(b)

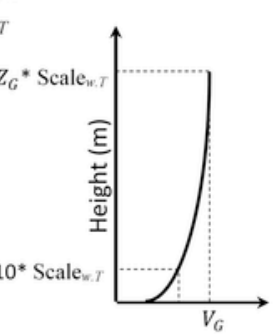

Wind Speed $(\mathrm{m} / \mathrm{s})$

Fig. 4. : Schematic for Wind Energy Potential Estimation by using (a) Computations based on Meteorological Data. (b) Wind Tunnel Modeling Approach. 


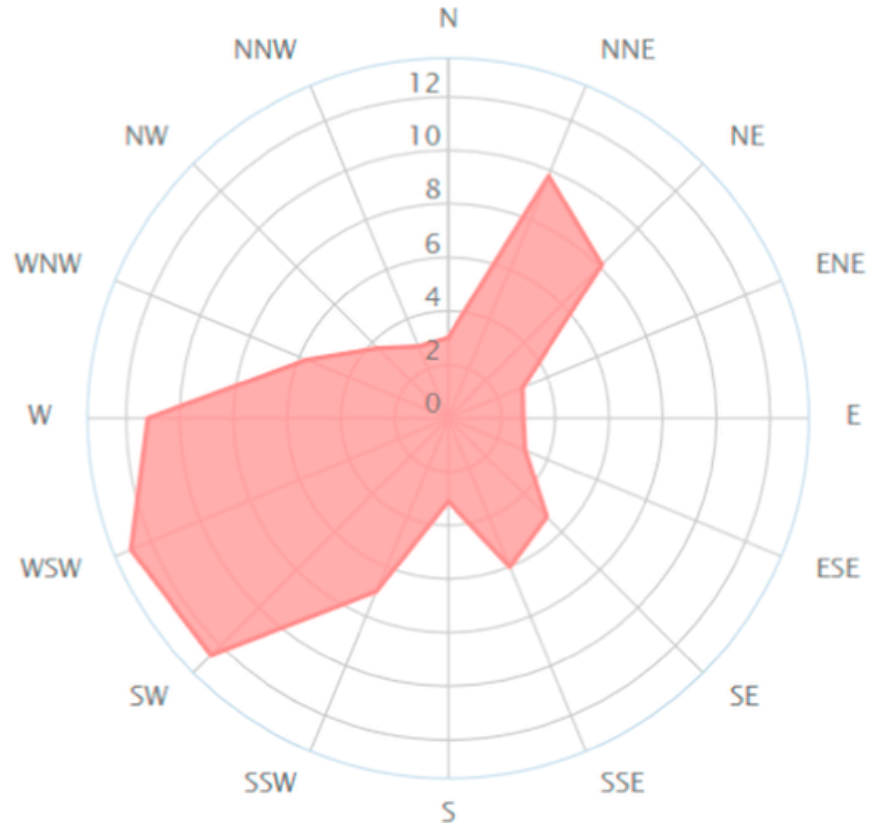

Fig. 5. : Yearly Wind Rose of Montreal [Wind Direction Distribution in \%] (based on data from 2007 to 2016) (http://www.windfinder.com/windstatistics/ dorval_lake_saint_louis).

By dividing Eqs. (3) and (2), the relation between $\left(v_{2}\right)$ and $\left(v_{1}\right)$ can be obtained as follows:

$$
\begin{aligned}
\frac{v_{2}}{v_{1}} & =\frac{\left(\frac{Z_{X}}{z_{G U r b}}\right)^{\alpha_{U r b}}}{\left(\frac{10}{z_{G O . T}}\right)^{\alpha_{O . T}}} \\
& \Longrightarrow v_{2} \\
& =v_{1} \times \frac{\left(\frac{Z_{X}}{z_{G U r b}}\right)^{\alpha_{U r b}}}{\left(\frac{10}{z_{G O T}}\right)^{\alpha_{O . T}}} \\
& =v_{1} \times \text { CorrectionFactor }
\end{aligned}
$$

The wind speed at a specific position on top of the building roof can be calculated as follows:

$$
v_{3}=\text { Ratio } \times v_{2}
$$

where this ratio can be obtained using wind tunnel tests as follows:

$$
\text { Ratio }=\frac{v_{3 w . T}}{v_{2 w . T}}
$$

and:

$v_{3 w . T}$ wind speed measured in the wind tunnel at a specific position above the roof of building $\mathrm{X}$ in the model.

$v_{2 w . T}$ wind speed measured in the wind tunnel at the corresponding position upstream of the site of interest.

In order to find these ratios, physical models for building $\mathrm{X}$ and the surroundings have to be built and tested in the wind tunnel, as shown schematically in Fig. 4(b).
Using this methodology, a complete local wind rose at a specific position above the roof can be obtained to be used in the wind energy estimation as follows:

$$
E_{3}=\frac{1}{2} \rho v_{3}^{3} T
$$

where:

$E_{3}$ wind energy above the roof of building X produced in T hours

This is the theoretically estimated value. However Betz's law provides the maximum energy that can be extracted from the wind. According to this limit, no HAWT can capture more than 16/27 (59.3\%) of the kinetic energy in wind. For VAWT, some recent theoretical research (Lecanu et al., 2016) has shown that active lift turbines can deliver power coefficients greater than defined by Betz for classical vertical axis Darrieus type turbines. Practically, wind turbines cannot extract more than $75-80 \%$ of the Betz limit. However, this paper discusses the estimation of the wind energy potential rather than the actually extracted energy by the wind turbine(s). Also, in order to study the variation of the data from their average values, the standard deviation $(\sigma)$ has been used to implement this effect.

This methodology was tested for two building cases with different surroundings and upstream terrains, one homogenous, the other nonhomogeneous in Montreal:

- EV building case (rather homogeneous terrain).

- Equiterre building case (nonhomogeneous terrain).

\section{Testing the methodology using a rather homogeneous terrain}

A case study of wind energy estimation using the wind tunnel has been applied to the EV building, which is the engineering complex of Concordia University. The height of the EV building is around $76 \mathrm{~m}$. Fig. 6 shows the location of the EV building and the surrounding areas.

In order to compare the calculated wind energy using the field measurements over the EV building roof and the estimated value using the proposed methodology, a three-cup anemometer was installed in one roof corner at a height of $2 \mathrm{~m}$ above the roof. The anemometer was programed to take one measurement every $5 \mathrm{~s}$. The field measurement data were collected from the beginning of August 2013 to the end of October 2013. The obtained data were used to calculate the total wind energy for the corresponding period. Fig. 7(a) and (b) show the monthly average wind speed above the roof of the EV building and the calculated total wind energy respectively using the field measurement data. The corresponding error bars based on the variability of the data are also shown in Fig. 7(a) and (b).

One year of wind speed data was obtained from Dorval (PET) Airport sensor from the beginning of November 2012 to the end of October 2013 for use in the energy estimation above the roof of the EV building (http://climate.weather.gc.ca/climateData/ hourlydata e.html?timeframe $=1 \&$ Prov $=$ QUE \&StationID $=5415 \&$ hlyRange $=195$ $14 \&$ Year $=2012 \&$ Month $=11 \&$ Day $=2$ ). The wind tunnel tests in this case were carried out using the model of the EV building available in the wind tunnel laboratory of Concordia University. Fig. 8 shows the EV building model and the surrounding area. Using Eq. (4) and by considering a power-law exponent $(\alpha)$ of 0.22 which is applicable in this case, a correction factor was used to estimate the wind speed in the upstream of the roof of the EV building at the same height of the installed anemometer. This correction factor is calculated as follows: 


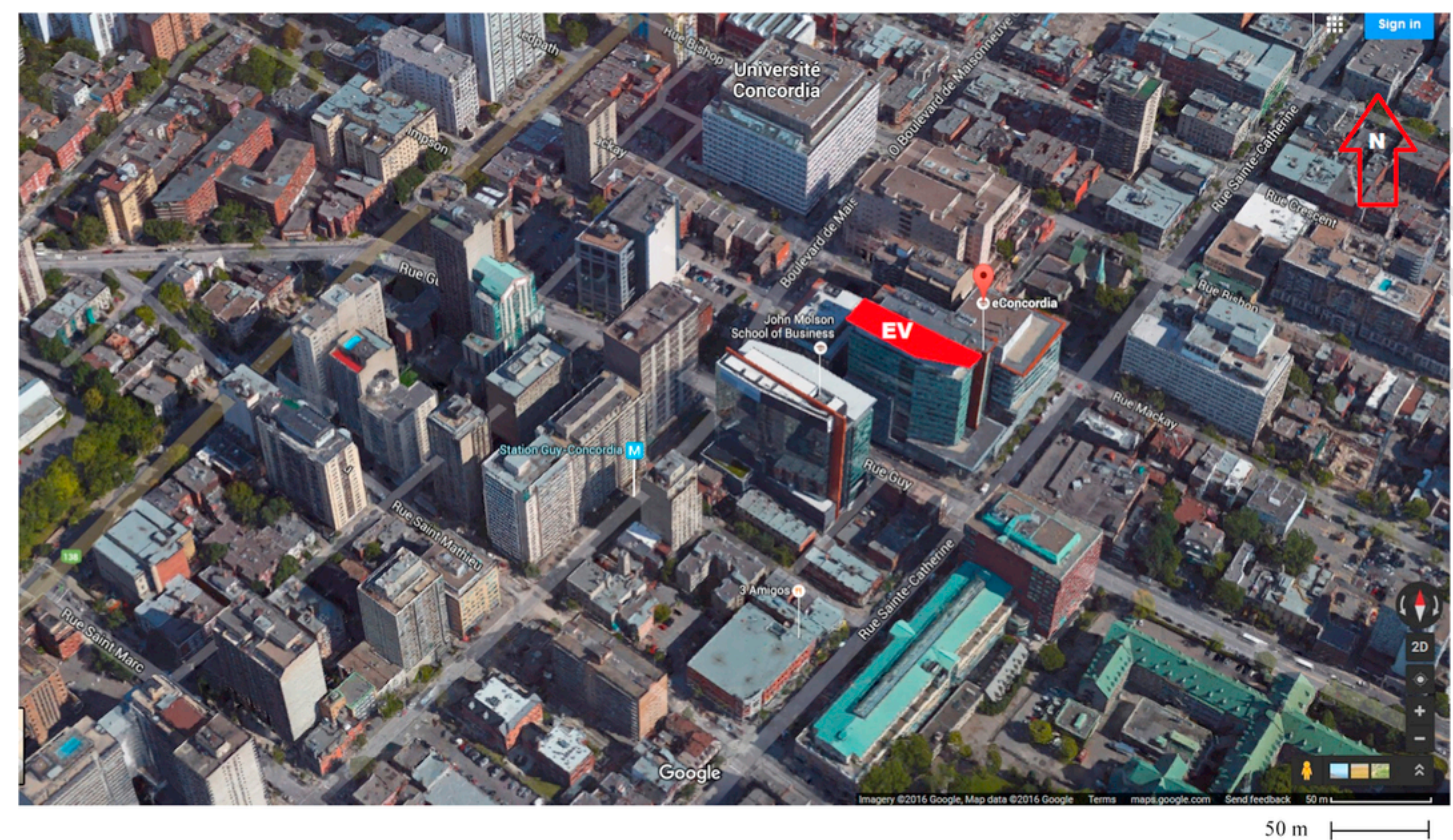

Fig. 6. : 3D Perspective View of the EV Building and the Surrounding Area (https://www.google.ca/maps)

$$
\text { CorrectionFactor }=\frac{\left[Z_{E V} / Z_{\text {GS.Urb }}\right]^{\alpha_{S . U r b}}}{\left[10 / Z_{\text {GO.T }}\right]^{\alpha_{O . T}}}=\frac{[78 / 370]^{0.22}}{[10 / 300]^{0.15}}=1.18
$$

where:

$Z_{E V}$ Height of the installed anemometer above the roof of the EV building (measured

from the ground).

The wind speed upstream the EV building $\left(v_{2_{E V}}\right)$ can then be calculated as:

$$
v_{2_{E V}}=\text { Correction Factor } X v_{1}=1.18 X v_{1}
$$

The ratios of the upstream wind speed to the wind speed above the roof of the EV building from different directions were measured using the wind tunnel tests. These ratios - shown in Table 2 - were included in the estimation of the wind speed at the same position of the anemometer by using Eq. (5) to obtain a complete hourly wind rose for the duration of one year. Then the hourly wind speeds were averaged for each month to be used in energy estimation. Comparisons between the field measurements of wind speed and corresponding wind energy and their estimation are shown in Fig. 9(a) and (b) respectively. It can be shown that the error in the wind energy, evaluated by [(field - estimated)/field] $* 100 \%$, is less than $5 \%$, as shown in Table 3 which means that this methodology is sufficiently accurate to be used, at least in the case of homogeneous terrain. Using the estimated wind speed profile for a duration of one year, the wind energy potential was evaluated for the corresponding period using Eq. (7). Fig. 10(a) and (b) show the estimated wind speed and potential wind energy for this building.

\section{Testing the methodology using a nonhomogeneous terrain}

In order to generalize the use of this methodology, another case study was applied to Equiterre building, which is the Center for Sustainable Development, a nonprofit organization whose mission is to build and operate a certified green building. This demonstration project aims to share space and resources with other social and environmental organizations and provide citizens, businesses and governments with information on sustainable development in Canada. Equiterre building is $23 \mathrm{~m}$ high and it is surrounded by three high-rise buildings, as shown in Fig. 11. These buildings are:

- Hydro-Quebec building which is $113 \mathrm{~m}$ tall.

- Complex Desjardins, which consists of two separate buildings:

1. Building 1 which is $123 \mathrm{~m}$ tall.

2. Building 2 which is $100 \mathrm{~m}$ tall.

The Equiterre building is around $20 \mathrm{~km}$ North-East from Dorval (PET) Airport.

A three-cup anemometer was installed in one corner above the roof of the Equiterre building, identical to the one on the roof of the EV building and with the same settings. The field measurement data magnitude of the wind speed only - were collected for a 3-month period: November 1, 2012 to January 31, 2013. These field data were used for wind energy calculations. Fig. 12(a) and (b) show the average wind speed and the total wind energy above the roof of the Equiterre building. These data were significantly reduced in comparison to those obtained from the EV building - see Fig. 7 - but this was expected due to the lower height and the sheltering of the Equiterre building.

For the corresponding period of the field measurement data, the wind speed and the wind energy were also estimated using the same methodology. Using Eq. (4) again and by considering the fourth category in Table 1, which is applicable to this case, a correction factor of 0.63 , evaluated as in the case of the homogeneous terrain, was used to estimate the wind speed upstream of the building at the same 


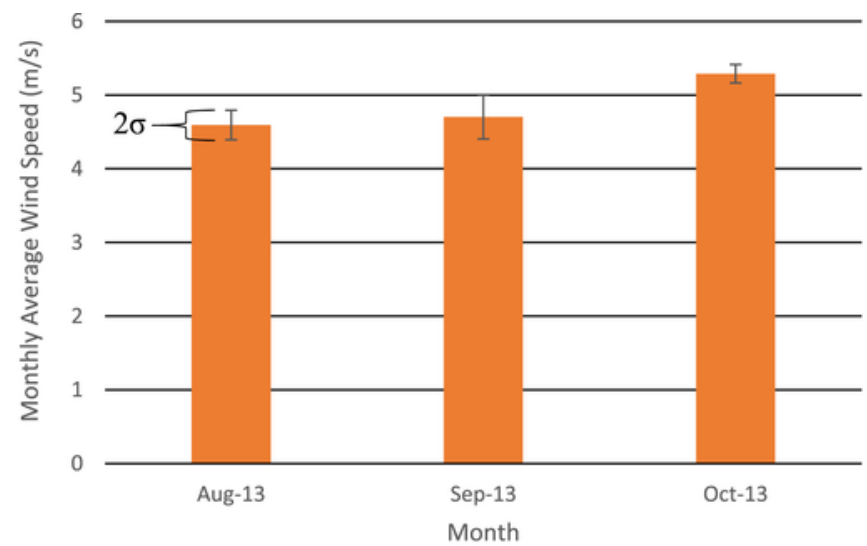

(a)

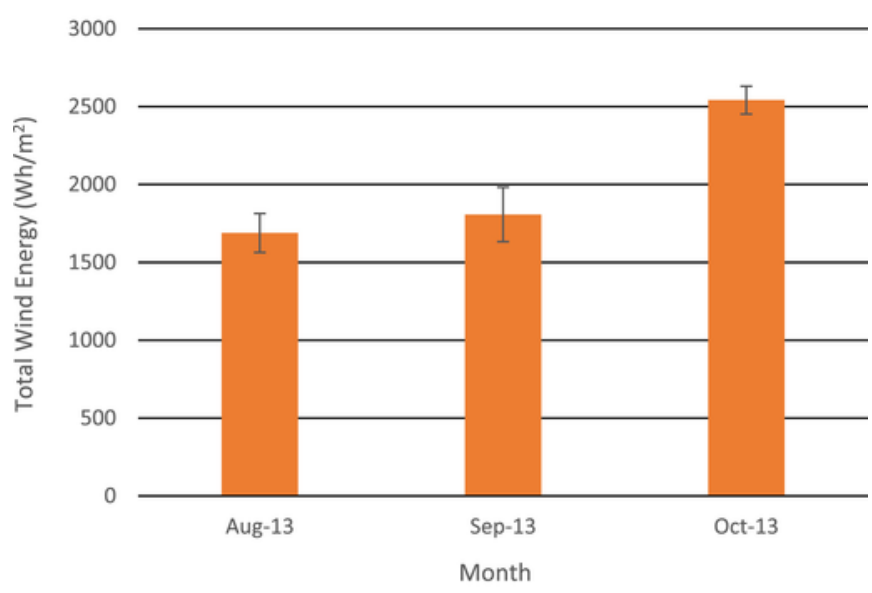

(b)

Fig. 7. : Field Measurement Data above the Roof of EV Building with the Corresponding Error Bars. (a) Average Wind Speed. (b) Total Wind Energy Potential per Unit Area.

height with the installed anemometer above the roof of Equiterre building:

$$
v_{2_{E q}}=\frac{[24 / 460]^{0.33}}{[10 / 300]^{0.15}} \times v_{1}=0.63 \times v_{1}
$$

where:

$v_{2_{E q}}$ wind speed upstream the building at the same height of the installed anemometer over Equiterre building.

In order to estimate the wind speed above this building, wind tunnel measurements were again carried out to find the ratio between the wind speed upstream to the wind speed above the roof of the Equiterre building. For this purpose a complete model of the Equiterre Building and the surroundings was built to a scale of 1:400 and tested in the wind tunnel, as shown in Fig. 13. The simulated wind flow in the wind tunnel was used to evaluate the ratios from several wind directions as in the case of the homogeneous terrain. Table 4, similarly with Table 2 , shows the wind directions and their corresponding ratios. It can be shown from Table 4 that there is a significant variation in the ratios of the Equiterre building case. This is due to the inhomogeneity in the surrounded buildings, as previously discussed.

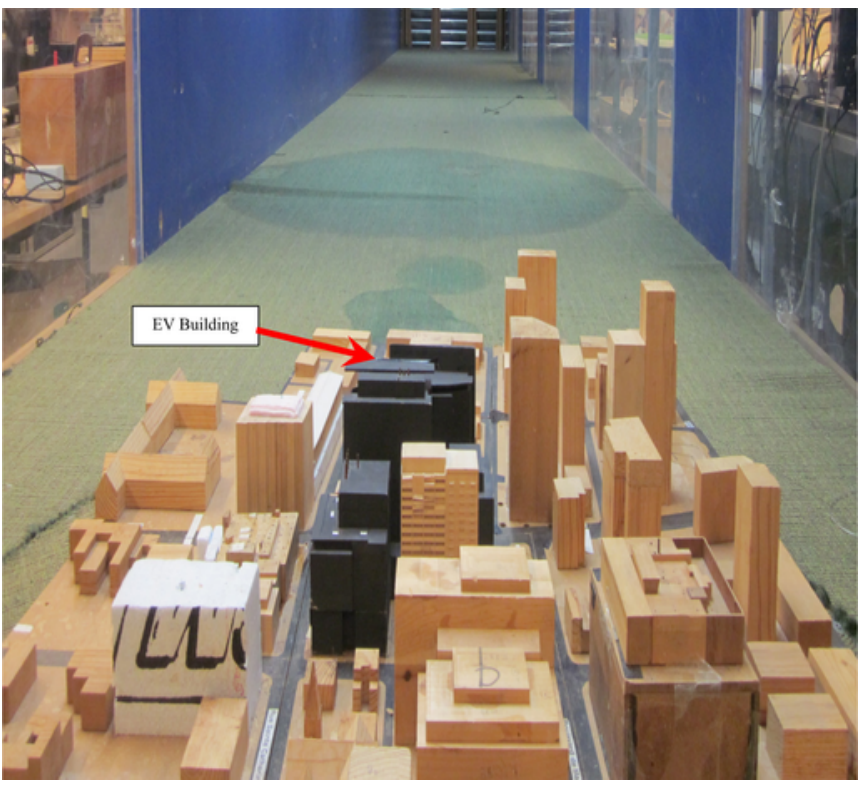

Fig. 8. : EV Building model with surroundings above the turntable in the wind tunnel (Direction of the wind is South-West).

Table 2

Wind directions in the Wind Tunnel Tests and Corresponding Ratios for EV Building (Eq. (6)).

\begin{tabular}{llll}
\hline Direction & Ratio & Direction & Ratio \\
\hline 1 & 0.98 & 21 & 1.06 \\
3 & 0.95 & 22 & 0.99 \\
5 & 0.98 & 23 & 0.94 \\
7 & 1.07 & 24 & 0.91 \\
9 & 1.10 & 25 & 1.01 \\
11 & 1.13 & 26 & 1.06 \\
13 & 0.93 & 27 & 1.17 \\
15 & 1.06 & 29 & 1.02 \\
18 & 0.96 & 31 & 1.09 \\
19 & 1.11 & 33 & 0.98 \\
20 & 1.02 & 35 & 0.93 \\
\hline
\end{tabular}

If $v_{3 \mathrm{Eq}}$ is the wind speed profile for one year estimated above the roof of Equiterre building, then:

$v_{3_{E q}}=$ Ratio $\times v_{2_{E q}}$

As in the previously discussed rather homogeneous terrain case, a complete hourly wind speed profile for one year was obtained. Then the wind speeds were averaged for each month to be used for power and energy estimation. A comparison between the estimated wind speeds and estimated wind energy with the field measurement values are shown in Fig. 14(a) and (b), as in the previous case.

The obtained results show that the error between the wind energy field measurement and the estimation using the wind tunnel is less than $20 \%$, as shown in Table 5, which means that this method can be used in the case of nonhomogeneous upstream terrain but for initial stages of potential wind energy estimation only. Using the estimated wind speeds for a duration of one year, the potential wind energy was evaluated for the corresponding period using Eq. (7), as in the previous case. Fig. 15(a) and (b) show the estimated monthly average wind speed and total energy for the Equiterre building case. 


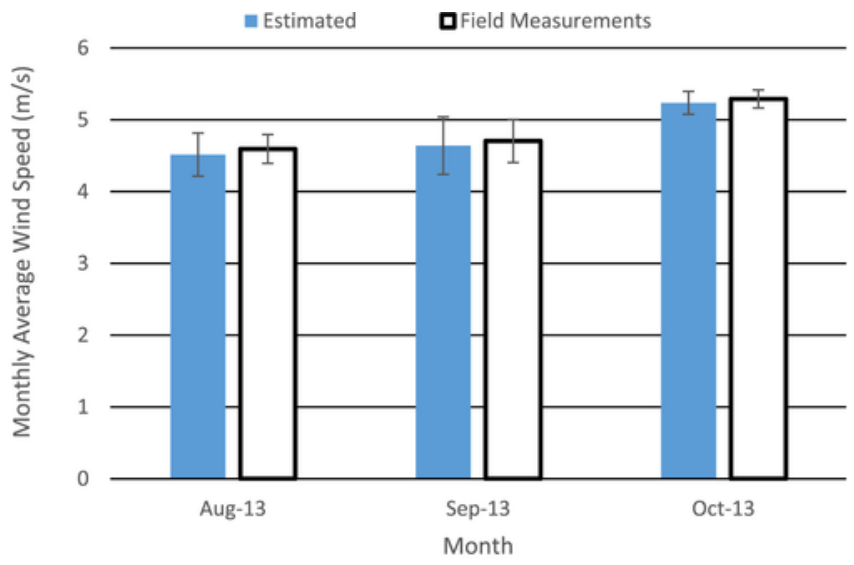

(a)

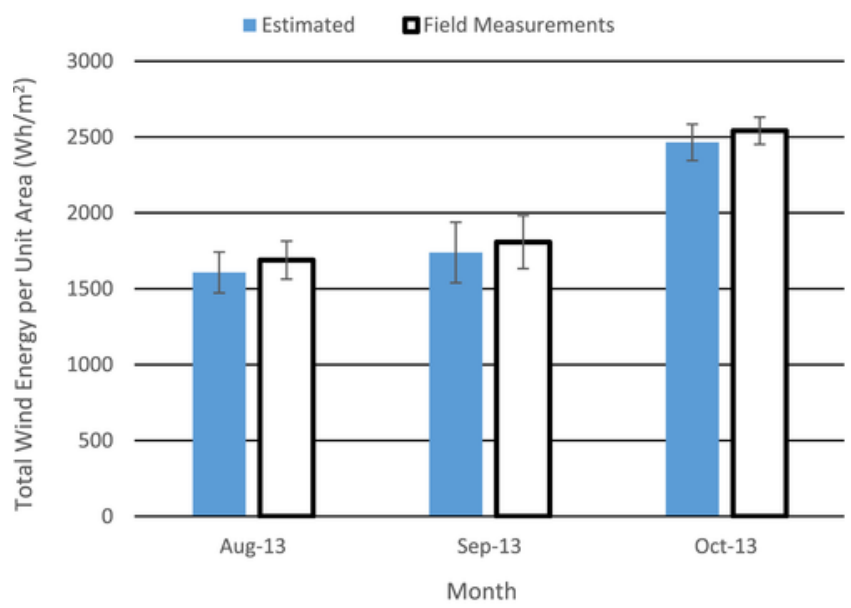

(b)

Fig. 9. : Field Measurement Data and Estimated Values above the Roof of EV Building with the Corresponding Error Bars. (a) Average Wind Speed. (b) Total Wind Energy Potential per Unit Area.

Table 3

Error in the Estimation of Potential Wind Energy at the Roof of EV Building - found by Comparison with Full Scale Results.

\begin{tabular}{ll}
\hline Month & Error (\%) \\
\hline August 2013 & 4.8 \\
September 2013 & 3.8 \\
October 2013 & 3.0 \\
\hline
\end{tabular}

\section{Conclusion and recommendations}

This paper compares wind tunnel results with corresponding field measurement wind data in order to examine the validity of wind tunnel in providing realistic estimates of urban wind energy potential and assess the probable errors involved in the process. Two building case studies in Montreal were discussed in this paper. In the case of rather homogeneous terrain, the results show high correlation between the estimation of the wind energy using the wind tunnel approach and the calculation based on field measurements above the roof of a building. In the second case, where the terrain is highly non-

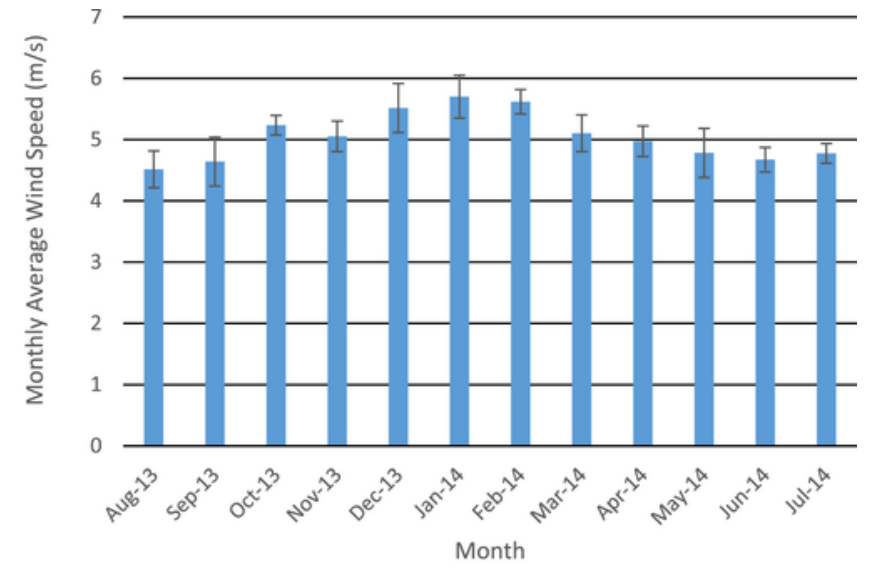

(a)

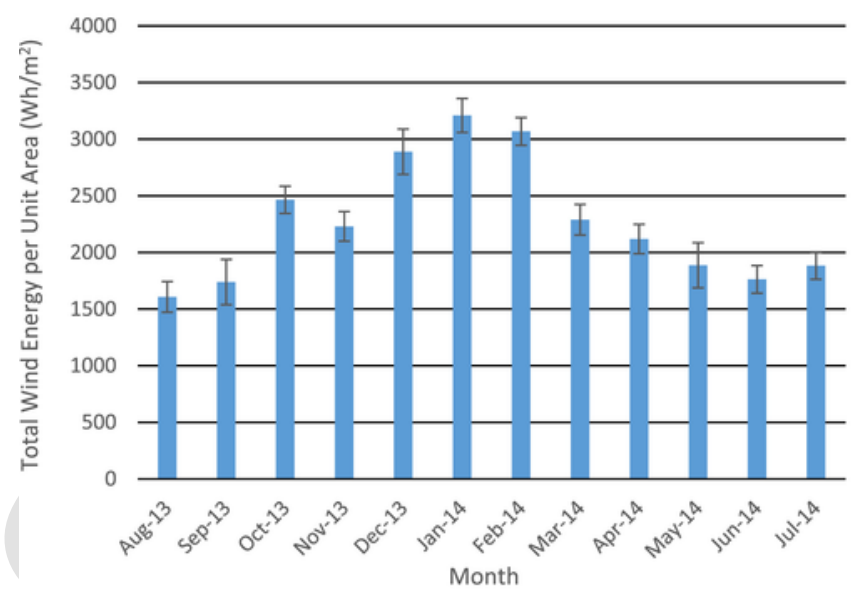

(b)

Fig. 10. : Estimated Values above the Roof of EV Building for a One-Year Duration with the Corresponding Error Bars. (a) Average Wind Speed. (b) Total Wind Energy Potential per Unit Area.

homogeneous, the discrepancy is higher but may still be acceptable for purposes of initial evaluation.

In general, the accuracy of the wind tunnel approach depends on the complexity of the upstream terrain. The error of estimating potential wind energy varies from $5 \%$ to $20 \%$. This approach is very useful to estimate the wind potential before a building is built or before a wind turbine installation takes place, so that a decision can be made on the type of renewable energy power generation to be used.

Further research would be desirable to examine different wind climates and the effect of turbulence intensity, the high values of which in the urban environment is presently a deterrent for the utilization of urban wind energy. Any means to reduce the turbulence intensity by streamlining the oncoming wind flow prior to interacting with the wind energy generator deserve further study and investigation.

\section{Acknowledgements}

The authors acknowledge the support to the first author by a scholarship from Yarmouk University, Jordan, as well as, the Faculty of Engineering and Computer Science of Concordia University in terms of the Graduate Student Support Program (GSSP). The authors are grateful to Professor Charalambos C. Baniotopoulos, member of the journal's Editorial Board, who kindly agreed to be Acting Editor 


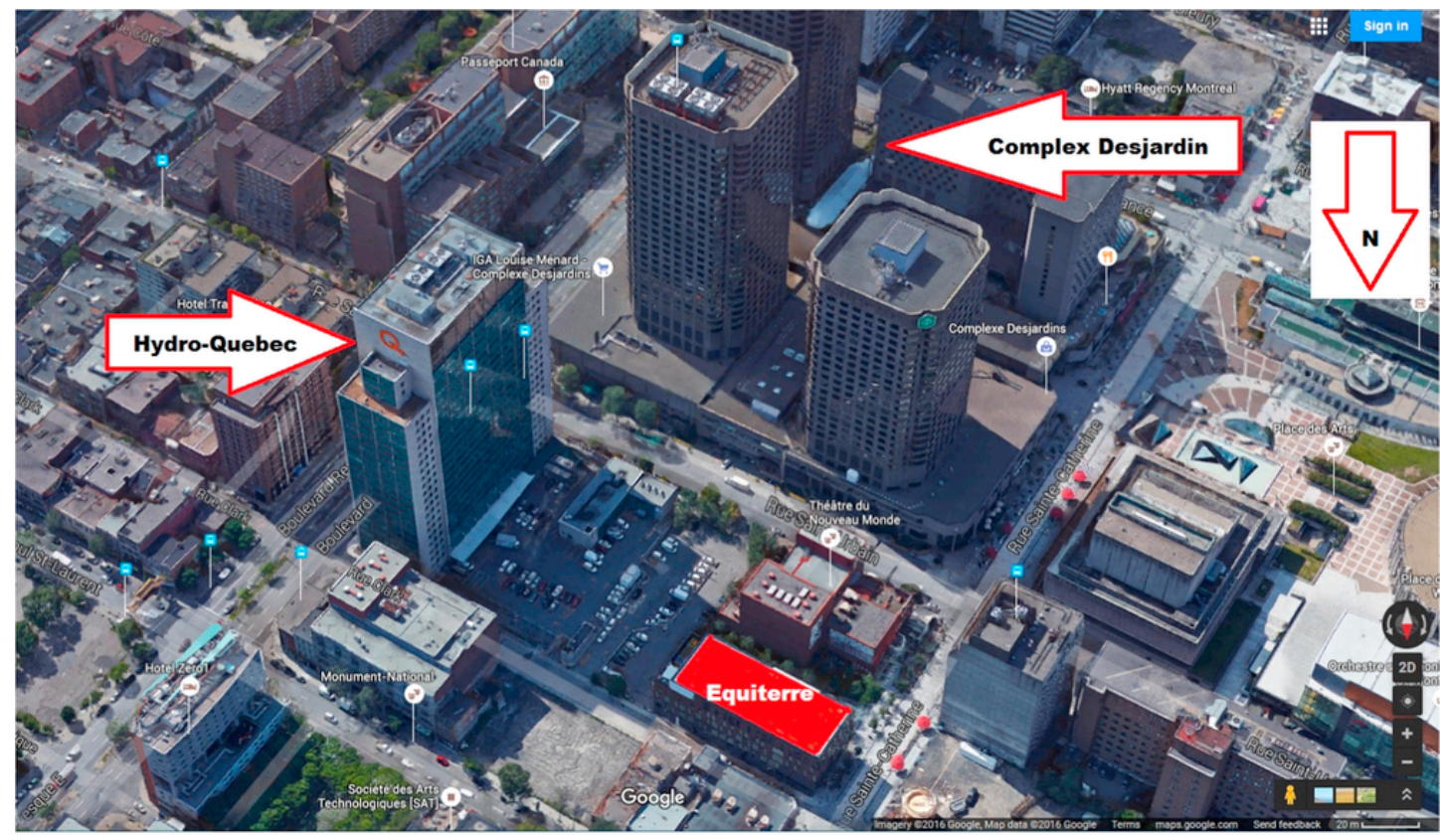

$20 \mathrm{~m}$

Fig. 11. : 3D Perspective View of Equiterre Building and the Surrounding Area (https://www.google.ca/maps).

and handled the review process for this paper outside the EVISE system, since the Editor is a co-author. Finally, the constructive com- ments and suggestions made by the reviewers have been greatly appreciated. 


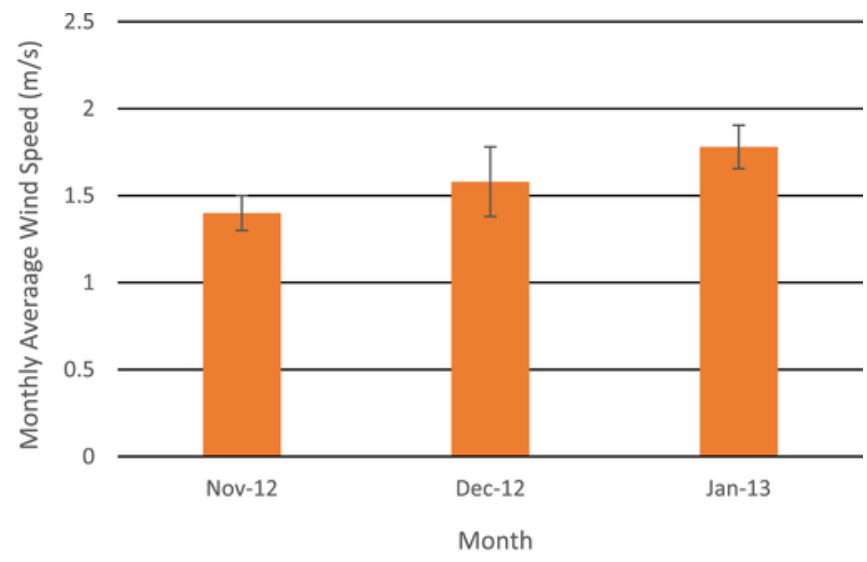

(a)

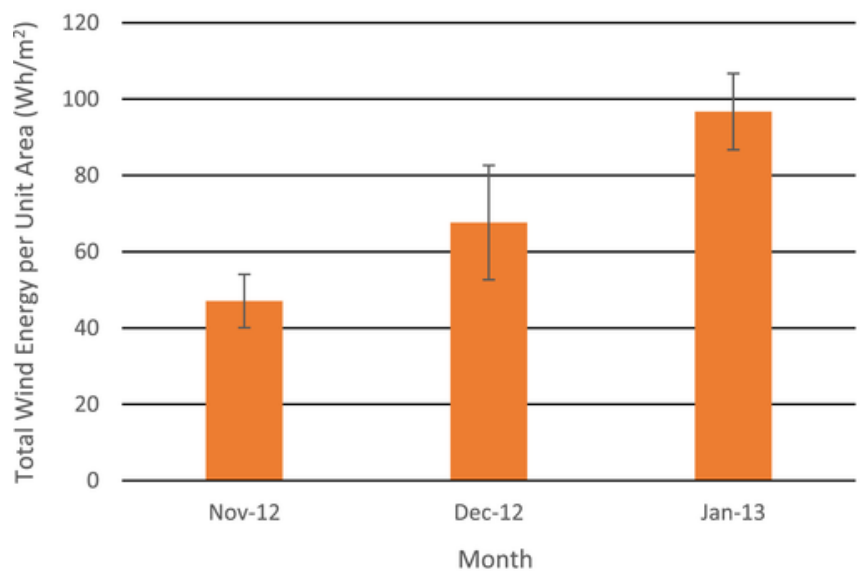

(b)

Fig. 12. : Field Measurement Data above the Roof of Equiterre Building and the Corresponding Error Bars. (a) Average Wind Speed. (b) Total Wind Energy per Unit Area. 


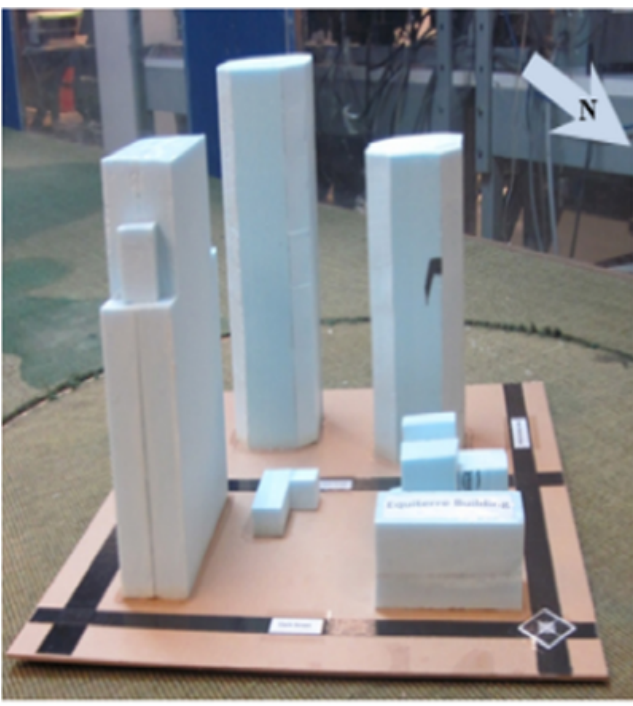

(a)

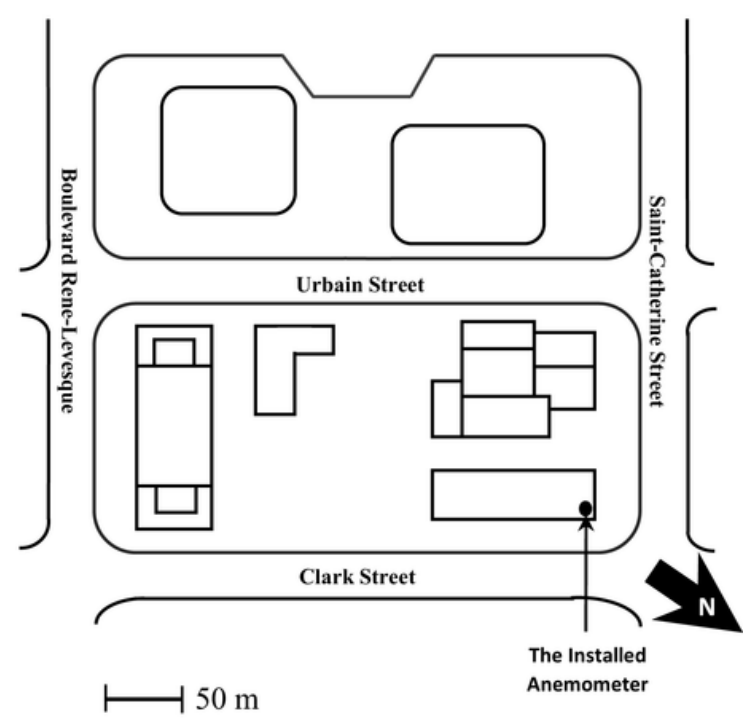

(b)

Fig. 13. : Equiterre Building Model: (a) with Surrounding Buildings. (b) Rooftop Location of 3-Cup Anemometer.

Table 4

Wind Directions in the Wind Tunnel Tests and Corresponding Ratios for Equiterre Building (Eq. (6)).

\begin{tabular}{llll}
\hline Direction & Ratio & Direction & Ratio \\
\hline 1 & 0.98 & 21 & 0.46 \\
3 & 0.95 & 22 & 0.49 \\
5 & 0.98 & 23 & 0.54 \\
7 & 1.07 & 24 & 0.91 \\
9 & 1.10 & 25 & 1.00 \\
11 & 1.00 & 26 & 1.10 \\
13 & 0.56 & 27 & 0.93 \\
15 & 0.20 & 29 & 1.00 \\
18 & 0.36 & 31 & 1.10 \\
19 & 0.45 & 33 & 0.98 \\
20 & 0.50 & 35 & 0.93 \\
\hline
\end{tabular}




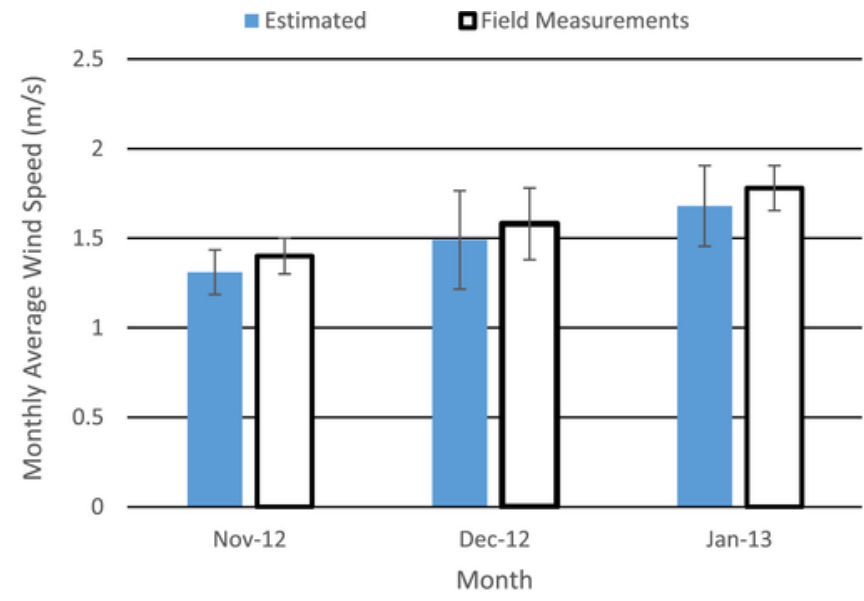

(a)

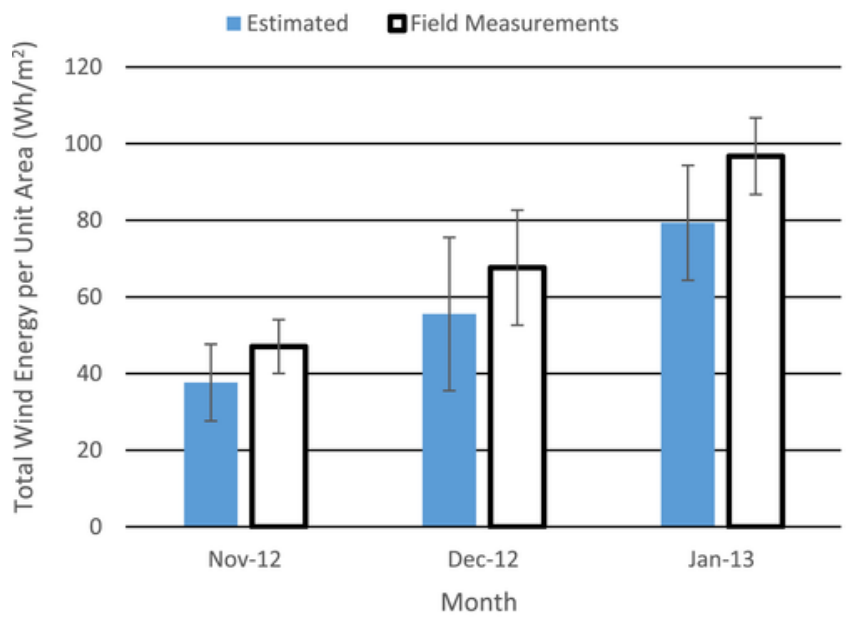

(b)

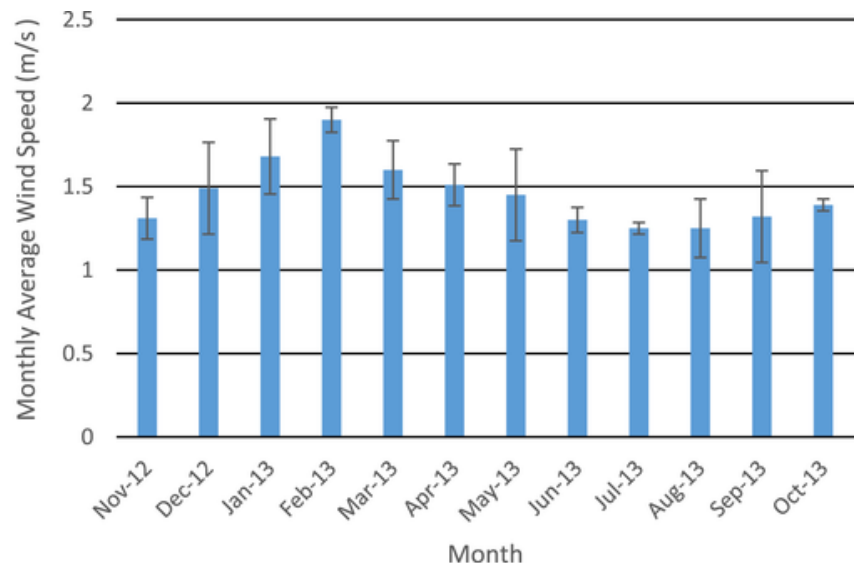

(a)

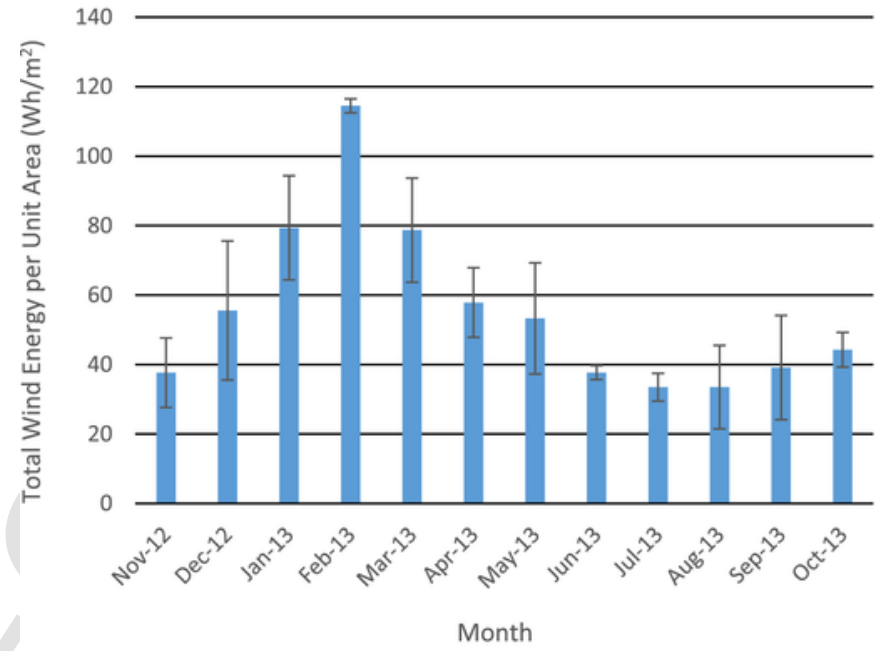

(b)

Fig. 15. : Estimated Values above the Roof of Equiterre Building for a One-Year Duration with the Corresponding Error Bars. (a) Average Wind Speed. (b) Total Wind Energy Potential per Unit Area.

Al-Quraan, A., Pillay, P., Stathopoulos, T., 2014b. Estimation of urban wind energy equiterre building case in Montreal. In: Proceeding of the 14th Civil Engineering for Sustainability and Resilience (CESAR'14), Jordan, April 2014.

Table 5
Error in the Estimation of Potential Wind Energy at the Roof of Equiterre Building found by Comparison with Full Scale Results.

\begin{tabular}{ll}
\hline Month & Error (\%) \\
\hline August 2013 & 19.9 \\
September 2013 & 17.8 \\
October 2013 & 17.9 \\
\hline
\end{tabular}

\section{References}

Al-Quraan, A., Pillay, P., Stathopoulos, T., 2014a. Use of a wind tunnel for urban wind power estimation. In: Proceedings of the IEEE Power and Energy Society General Meeting (PES), Washington, July 2014.
Arriago, L., 2009. Wind energy in the built environment: A design, analysis using CFD and tunnel modelling approach ( $\mathrm{PhD}$ Thesis). University of Nottingham, England, 2009.

Davenport, A.G., 1960. Rationale for determining design wind velocities. J. Struct. Eng., ASCE Vol. 86, 39-68.

European Commission, 2007. Report about the wind resource assessment in the urban environment..

Heath, M., Walshe, J., Watson, S., 2007. Estimating the potential yield of small building-mounted wind turbines. Wind Energy 10, 271-287.

http://beforeitsnews.com/environment/2010/11/urban-rooftop-wind-turbines-254292.html (accessed 25. 04.16.).

http:/climate.weather.gc.ca/climateData/hourlydata e.html?timeframe $=1 \&$ Prov $=$ QUE $\&$ StationID $=5415 \&$ hlyRange $=1953-01-01 \mid 2013-02$ $14 \&$ Year=2012\&Month=11\&Day=2(accessed 25.04.16.).

$\mathrm{http}: / /$ inhabitat.com/venger-wind-unveils-worlds-largest-rooftop-wind-farm-in-oklahoma-city/(accessed 25.04.16.). 
http://www.bing.com/maps/ (accessed 25.04.16.).

http://www.climate.weatheroffice.gc.ca/prods_servs/glossary_e.html\#elevation, (accessed 25.04.16)

http://www.cundall.com/Cundall/fckeditor/editor/images/UserFilesUpload/file/ WCIYB/IP-27\%20-\%20Wind\%20turbine\%20performance.pdf (accessed 25.04.16).

http://www.dailyenmoveme.com/en/renewable/small-wind-turbine/ropatec-vertical-axis-wind-turbines , (accessed 25.04.16.).

http://www.quartierdesspectacles.com/en/location/168/maison-du-developpement-durable/page-1 (accessed 25.04.16.).

http://www.windatlas.ca (accessed 17.09.13.).

http://www.windfinder.com/windstatistics/dorval_lake_saint_louis (accessed 25.04.16).

https://commons.wikimedia.org/wiki/File:Bahrain_World_Trade_Center.jpg?uselang=nl (accessed 17. .08.16.).

https://en.wikipedia.org/wiki/Strata_SE1(accessed 25.04.16.).

https://maps.google.ca/maps?hl=en\&tab=wl (accessed 25.04.16.).
Lecanu, P., Breard, J. and Mouazé, D., 2016. Simplified Theory of an Active Lift Turbine with Controlled Displacement, $<$ hal-01300531v2 $>$ (accessed 3.08.16.).

Mathew, S., Pandey, K.P., Kumar, A., 2002. Analysis of wind regimes for energy estimation. Elsevier Renew. Energy 25 (3), 381-399.

Renewable Energy Resources, Second edition, John Twidell and Tony Weir, Dec. 2005, London and New York.

Stathopoulos, T., 1984. Design and fabrication of wind tunnel for building aerodynamics. J. Wind Eng. Ind. Aerodyn. Vol. 16, 361-376.

Stathopoulos, T., 2007. (Chapter 1). Wind Effects on Buildings and Design of Wind-Sensitive Structures. Springer, Wien New York.

Stathopoulos, T., Lazure, L., Saathoff, P., 1999. Tracer gas investigation of reingestion of building exhaust in an Urban Environment. Technical Report. IRSST

Sunderland, K., Conlon, M., 2010. Estimating the yield of micro wind turbines in an urban environment: a methodology. In: Proceedings of the Universities Power Engineering Conference (UPEC), 31 Aug. 2010-3 Sept. 2010, pp. 1-6.

Vasan, N., Stathopoulos, T., 2014. Experimental study of wind effects of unglazed transpired collectors. Sol. Energy 101, 138-149. 